\title{
Perceptions of a Pragmatic Family-Centered Approach to Childhood Obesity Treatment
}

\author{
Betty M. Kennedy, PhD, ${ }^{1}$ Genevieve Davison, MPH, ${ }^{2}$ Lauren A. Fowler, $\mathrm{PhD},{ }^{2}$ Erika Rodriguez-Guzman, BA, ${ }^{1}$ Myra \\ L. Collins, LPN, ${ }^{1}$ Alison Baker, MS, ${ }^{3}$ Stephen Cook, MD, ${ }^{4}$ Jeanne Lindros, MPH, ${ }^{3}$ Denise E. Wilfley, PhD, ${ }^{2}$ Ava \\ J. Zebrick, MSHCM, ${ }^{1}$ Amanda E. Staiano, PhD $^{1}$ \\ ${ }^{1}$ Pennington Biomedical Research Center, Baton Rouge, LA 2 Department of Psychiatry, Washington University School of Medicine, St. \\ Louis, MO ${ }^{3}$ American Academy of Pediatrics, Itasca, IL ${ }^{4}$ Department of Research, Golisano Children's Hospital, University of Rochester \\ Medical Center, Rochester, NY
}

Background: Few studies have examined both parent and child preferences regarding family-based weight management programs (WMPs) delivered in primary care settings, especially among racial minority populations. The purpose of this study was to determine the perceptions that parents and their children/adolescents have about the components that should be included in a family-based WMP and to identify perceived preferences, benefits, and/or barriers to participation.

Methods: A sample of 60 participants (30 parents and 30 children/adolescents) participated in 1 of 5 separate structured focus groups, using probing questions and the nominal group technique (NGT). Parents reported demographics for themselves and their children/adolescents. Themes from probing questions were identified using thematic analysis.

Results: Parents were primarily African American (93\%) and diverse in income. NGT sessions revealed that parents across all groups perceived that education on healthy eating, parental involvement, and effective program leaders are most important and have the greatest impact, while parental involvement was perceived as the easiest method to implement in a family-based WMP for childhood obesity. Children/adolescents perceived that education on healthy eating and exercise would have the greatest impact, while healthy eating and meal plans were perceived as the easiest methods to implement with a family. Parents and children/adolescents also identified improved psychological well-being (eg, decreased bullying, increased self-esteem, and motivation) as a desired program outcome.

Conclusion: Parents and their children/adolescents highlighted the importance of physical and psychological health as targets in treatment. Feedback from patients can inform the design and implementation of family-based WMPs delivered in primary care settings.

Keywords: Pediatric obesity, primary health care, weight loss, weight reduction programs

Address correspondence Amanda E. Staiano, PhD, Pennington Biomedical Research Center, 6400 Perkins Rd., Baton Rouge, LA 70808. Tel: (225) 763-2729. Email: amanda.staiano@pbrc.edu

\section{INTRODUCTION}

Almost 1 in 5 youth (18.5\%) struggles with obesity, ${ }^{1,2}$ and $9.5 \%$ of adolescents have severe obesity (body mass index [BMI] $\geq 120 \%$ of the 95th percentile, or $\geq 35 \mathrm{~kg} / \mathrm{m}^{2}$ ). ${ }^{3}$ Treatment of childhood obesity is complicated by complex and multifactorial etiology, with a multitude of contributing factors including genetics, developmental effects, fetal programming and epigenetics, environment, behavioral and psychosocial issues, physical activity, medications, eating patterns, illness, and cultural and family norms. ${ }^{4}$ Additionally, many children and adolescents with obesity have lower health-related quality of life compared to children and adolescents with normal weight and suffer from harmful psychosocial stigma. ${ }^{5-7}$
Primary care providers (PCPs) are tasked with periodic screening of children's health and growth, and as a result, PCPs play a vital role in recognizing and addressing childhood obesity, a condition associated with substantial health and economic burdens. ${ }^{8-11}$ As of 2011, however, active participation from PCPs in assessing or managing children with overweight or obesity in primary care clinics was low, ${ }^{11}$ even though pediatricians can easily identify children with obesity. ${ }^{12}$ Therefore, equipping PCPs with effective prevention and treatment tools to address childhood obesity that can be easily implemented is essential. Qualitative research published in 2016 shows that parents of children with overweight or obesity would like PCPs to take an active role in identifying child overweight or obesity and helping parents manage their children's weight. ${ }^{13,14}$ 
A common modality of multidisciplinary treatment for children with obesity is family-based weight management programs (WMPs), where parents and children attend sessions with a trained counselor or coach together as a family. ${ }^{15}$ Family-based behavioral treatments (FBTs) that simultaneously target children and their parents are effective ways to promote weight loss and management through healthy eating and exercise. ${ }^{16-18}$ In FBT, parents are taught positive parenting techniques, including contingency management, environmental control, and ways to promote their child's selfregulatory skills through behavioral economics and social learning theory. ${ }^{19}$

Integrating FBTs into primary care settings either by placing trained coaches in primary clinics or training providers in FBT techniques could improve treatment reach and accessibility and provide PCPs with an effective treatment option for pediatric patients with overweight and obesity. Few models for successfully adapting FBTs for non-specialty settings are available, ${ }^{20}$ although some studies show promise. A randomized controlled trial of a family-based weight control program for preschool-aged children implemented in primary care was found to be effective at helping children lose weight. ${ }^{21}$ A pilot study evaluating the acceptability of groupbased FBT for older children in primary care found that such programs may be effective and acceptable but noted challenges with both recruitment and retention. ${ }^{22}$ The successful implementation of FBTs for pediatric obesity in primary care settings will require a better understanding of families' attitudes regarding family-based WMPs.

The purpose of this study was to determine the perceptions parents and their children/adolescents have about the components that should be included in a family-based WMP in a primary care setting and to identify perceived preferences, benefits, and/or barriers to participation. Previous research in this area has largely focused on parent or child/adolescent preferences regarding the role of PCPs in child/adolescent weight management or WMPs, ${ }^{13,14,23}$ but few studies have examined both parent and child/adolescent preferences regarding family-based WMPs delivered in a primary care setting. ${ }^{24-26}$ Information gathered from this study is important to adapt family-based weight loss interventions in PCP settings.

\section{METHODS \\ Participants}

Parents and their children/adolescents aged 6 to 17 years old who were able to speak and understand English were eligible to participate in 1 of 5 separate structured focus groups. We did not impose an a priori inclusion criterion based on BMI; rather, we sought participants with an interest in discussing weight loss and weight management strategies. Individuals with a cognitive impairment that would interfere with participation in a group discussion were not eligible.

Participants were recruited principally by word of mouth and flyers printed in church bulletins or distributed at schools. Word-of-mouth recruitment relied on a network of friends, colleagues, neighbors, and relatives of current and previous study participants to spread the word about the study to help us reach our goal. When participants arrived at the focus group location and prior to the start of each discussion, the researcher read aloud a group informed consent that explained all aspects of the focus group that are normally detailed in a written document. The researcher emphasized that participation was voluntary, and those who did not wish to participate were asked to leave the room prior to the start of the focus group discussion. By remaining in the room after the consent document was read, participants signaled their agreement to participate in the study. Light refreshments were provided, and each family received a $\$ 50$ stipend. The Pennington Biomedical Research Center Institutional Review Board reviewed and approved the study protocol, procedures, and consent form.

\section{Design and Procedures}

The nominal group technique (NGT), a qualitative method of data collection, was used to engage parents and their children/adolescents to obtain their perspective on the components that should be included in family-based WMPs. The NGT is a brainstorming tool for quality improvement and highly structured small group discussions and is used to elicit and prioritize a list of answers to a specific question. ${ }^{27-31}$ Similar to traditional focus groups, 4 to 12 participants per group may be considered appropriate for NGT sessions. $^{32}$

The multistep NGT design is useful for systematically stimulating meaningful interpersonal statements among participants by gathering equally weighted responses to a specific question that tends to offer valid representation of group views. ${ }^{33-36}$ With the NGT method, audio recording and transcription are not necessary because verbatim responses are written on a flipchart, thereby providing a concise summary of the session that is readily available for dissemination. Prior to conducting the NGT sessions, the investigative team articulated the specific question and then pilot tested it with staff members, including those with children having a desire to reduce their weight, to ensure that it would elicit meaningful responses.

Parents and at least one child/adolescent residing in or within an hour of Baton Rouge, Louisiana, participated in 1 of 5 separate NGT sessions. Each focus group consisted of 5 to 7 participants and was conducted on Saturday morning, Saturday at noon, or Thursday evening, beginning at the end of September and ending on the first day of November 2018. Three sessions were conducted at the Pennington Biomedical Research Center, 1 at a charter school, and 1 at an agricultural center in Opelousas, Louisiana. Each group session lasted for approximately 90 minutes.

After welcoming the participants and providing brief introductions, the facilitators discussed the purpose of the session and ground rules for participation. To initiate each session, facilitators discussed probing questions with parents and children/adolescents, including "What are the most important results you'd expect from a weight management program?"; "What would make you want to stick with a program, even if you and your child needed to attend the program every week for several months?"; "What factors might prevent your child and you from participation in a weight management program?"; and "If we are successful in developing curriculum and materials for a familybased weight management program, what would that look like?"

The facilitators (B.M.K., E.R.G.), accompanied by a cofacilitator (M.L.C.), posed the specific question to parents: 
"We are working with primary care providers to create a program to help treat obesity in children; what important factors should a program include to treat childhood obesity?" The children/adolescents were asked, "What sorts of things could your doctor or a health coach teach you to help you have a healthy weight?" In response to the specific question, the participants were asked to work silently and independently and to write down as many responses in short phrases as possible that represented their individual views. In a round-robin manner, the participants were then asked to share their answers (one response at a time) while the co-facilitator wrote each response verbatim on a flipchart without discussion. Each recorded response was discussed for the sole purpose of clarification and not for evaluation or debate as to its relative importance. During this step, the participants were asked to combine responses that were perceived to be significantly similar. Finally, during the voting phase, the parents and children/adolescents privately selected what they considered to be the top 3 items from the generated list of responses likely to have the greatest impact and then did a second separate ranking to identify ideas that would be the easiest to implement for weight management.

Each parent and child/adolescent prioritized their choices on their own and without discussing with others, assigned a rank of 3 to the most important strategy and 1 to the least important strategy and likewise for the easiest to implement. The facilitators recorded the votes on the flipchart in front of all participants and then tallied the votes for each response. A small number of idiosyncratic ideas were discarded, which is a standard procedure in the NGT. The main results were the top 3 strategies identified within each group; the secondary results were all other ideas. Through an iterative process, the facilitators categorized responses into common themes until consensus was obtained.

To identify other unique responses to focus group questions and to ensure that nuances in response were recognized given the exploratory nature of the study, the raw data for all probing and specific questions were coded. Specifically, authors G.D. and L.A.F. independently coded the facilitators' summarized responses from parent and child/adolescent focus groups to identify common themes in responses. Differences in coding of themes among coders were discussed, and consensus of thematic categories for each question was reached.

Demographic information was collected from parents using survey instruments that included age, ethnicity, sex, education, employment, annual household income, and marital and health status. In addition, parents self-reported their own height and weight and the height, weight, and grade level of their child/adolescent.

\section{RESULTS}

Selected demographic characteristics of the 60 focus group participants (30 parents, 30 children/adolescents) are shown in Table 1. The average BMl for parents was 34.7 $\mathrm{kg} / \mathrm{m}^{2}$ (range, 20.1 to $55.3 \mathrm{~kg} / \mathrm{m}^{2}$ ). Fifty percent of children/adolescents had a $\mathrm{BMI}>95$ th percentile.

\section{Nominal Group Technique Sessions-Parents}

Thirty parents participated in 1 of 5 NGT sessions and generated 81 responses to the question, "What important factors should a program include to treat childhood obesity?" During the clarification discussions, parents within and across all groups indicated that many of the responses were similar or nearly the same, and as a result, responses were amalgamated. The final list for the prioritization exercise consisted of 10 responses that were organized under 4 themes identified during the iterative process: educate on healthy vs unhealthy eating, parental involvement, effective program leaders, and incentives.

Table 2 lists the 4 themes with representative parent responses next to each theme. The relative importance of parents' suggestions for what should be included in a familybased WMP is reflected by the total number of votes and the sum of ranks. The specific parent responses with the most votes were these: "Healthy eating guide to buy healthy foods or training for parents to educate children on how and why certain foods are healthy and not healthy for them"; "Mentor-eat with child; set the example of how to eat healthy"; "Coaching: reassurance no matter your size, no limits"; and "Fun, attractive to kids, and exciting to increase motivation."

Parents across all groups perceived the first 3 themeseducate on healthy vs unhealthy eating, parental involvement, and effective program leaders - as most important and likely to have the greatest impact, while parental involvement was perceived as the easiest method to implement in a family-based WMP. Secondary and other suggestions are categorized under each applicable theme displayed in Table 2.

\section{Nominal Group Technique Sessions-Children/ Adolescents}

Thirty children/adolescents participated in 1 of 5 NGT sessions and generated 46 responses to the question, "What sorts of things could your doctor or a health coach teach you to help you have a healthy weight?" During the clarification discussions, children/adolescents stated that several responses were repetitive, so responses were combined. The final list for the prioritization exercise consisted of 5 responses that were organized under 2 themes identified during the iterative process: educate on healthy vs unhealthy eating and exercise.

Table 3 lists the 2 themes with representative children/adolescent responses next to each theme. The relative importance of each response for what a doctor or health coach could teach them to have a healthy weight is reflected by the total number of votes and the sum of ranks. The specific children/adolescent responses with the most votes were these: "Recommend a good meal plan for each day per week to have the right nutrients and minerals to maintain a healthy body weight" and "Give you fun activities; play games, basketball, dodgeball, jumping jacks, dancing, and run with you to keep weight off."

Children/adolescents across all groups perceived these 2 themes-educate on healthy vs unhealthy eating and exercise-as most important and likely to have the greatest impact, while healthy eating and meal plans were perceived as the easiest methods to implement by a doctor or health coach to teach children/adolescents to have a healthy weight. Secondary and other responses are also noted under the applicable theme in Table 3. 
Table 1. Characteristics of Participants in the Focus Groups

\begin{tabular}{|c|c|c|c|c|}
\hline \multirow{2}{*}{$\frac{\text { Variable }}{\text { Age, years }}$} & \multicolumn{2}{|c|}{ Parents, $\mathbf{n}=\mathbf{3 0}$} & \multicolumn{2}{|c|}{ Children/Adolescents, $\mathbf{n}=\mathbf{3 0}$} \\
\hline & & & & \\
\hline $18-35$ & \multicolumn{2}{|l|}{$4(13)$} & \multicolumn{2}{|c|}{ Not available } \\
\hline $36-55$ & \multicolumn{2}{|l|}{$25(83)$} & & \\
\hline $56-65$ & \multicolumn{2}{|l|}{$1(3)$} & & \\
\hline \multicolumn{5}{|l|}{ Race } \\
\hline Black & \multicolumn{2}{|l|}{$28(93)$} & \multicolumn{2}{|c|}{ Not available } \\
\hline White & \multicolumn{2}{|l|}{$2(7)$} & & \\
\hline \multicolumn{5}{|l|}{ Sex } \\
\hline Female & \multicolumn{2}{|l|}{$30(100)$} & \multicolumn{2}{|c|}{$23(77)$} \\
\hline Male & \multicolumn{2}{|l|}{0} & \multicolumn{2}{|c|}{$7(23)$} \\
\hline \multirow[t]{6}{*}{ Education } & High school & $2(7)$ & 1st-2nd grade & $4(13)$ \\
\hline & $1-3$ years college & $8(27)$ & 3 rd-4th grade & $6(20)$ \\
\hline & College degree & $10(33)$ & 5 th-6th grade & $6(20)$ \\
\hline & Postgraduate degree & $10(33)$ & 7th-8th grade & $6(20)$ \\
\hline & & & 9th-10th grade & $7(23)$ \\
\hline & & & 11 th grade & $1(3)$ \\
\hline \multicolumn{5}{|l|}{ Employment } \\
\hline Full-time & \multicolumn{2}{|l|}{$26(87)$} & \multicolumn{2}{|c|}{ Not applicable } \\
\hline Part-time & \multicolumn{2}{|l|}{$2(7)$} & & \\
\hline Unemployed & \multicolumn{2}{|l|}{$1(3)$} & & \\
\hline Retired & \multicolumn{2}{|l|}{$1(3)$} & & \\
\hline \multicolumn{5}{|l|}{ Annual income ${ }^{a}$} \\
\hline$\$ 20,000-\$ 29,999$ & \multicolumn{2}{|l|}{$4(13)$} & \multicolumn{2}{|c|}{ Not applicable } \\
\hline$\$ 30,000-\$ 39,999$ & $6(20)$ & & & \\
\hline$\$ 40,000-\$ 49,999$ & $6(20)$ & & & \\
\hline$\$ 50,000-\$ 59,999$ & $2(7)$ & & & \\
\hline$\$ 60,000-\$ 69,999$ & $3(10)$ & & & \\
\hline$\geq \$ 70,000$ & $9(30)$ & & & \\
\hline Marital status & & & & \\
\hline Married & $15(50)$ & & Not a & \\
\hline Divorced/separated & $6(20)$ & & & \\
\hline Never married & $9(30)$ & & & \\
\hline Health status & & & & \\
\hline Excellent & $5(17)$ & & Not a & \\
\hline Very good & $9(30)$ & & & \\
\hline Good & $14(47)$ & & & \\
\hline Fair & $2(7)$ & & & \\
\hline Weight status & & & & \\
\hline Not overweight ${ }^{b}$ & $3(10)$ & & & \\
\hline Overweight or obesity ${ }^{c}$ & $27(90)$ & & & \\
\hline
\end{tabular}

Note: Data are presented as $\mathrm{n}(\%)$.

${ }^{a}$ Total household income.

${ }^{b}$ Body mass index $<25 \mathrm{~kg} / \mathrm{m}^{2}$ or $<85$ th percentile.

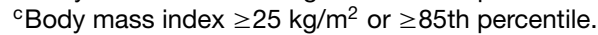


Table 2. Parents' Perceptions of Factors to Include in Family-Based Weight Management Programs $(n=30)$

\begin{tabular}{|c|c|c|c|}
\hline \multicolumn{4}{|c|}{$\begin{array}{l}\text { Specific question: We are working with primary care providers to create a program to help treat obesity in children; what } \\
\text { important factors should a program include to treat childhood obesity? }\end{array}$} \\
\hline Key Themes & Representative Responses & $\begin{array}{l}\text { Total } \\
\text { Votes }\end{array}$ & $\begin{array}{l}\text { Sum of } \\
\text { Ranks }^{\mathrm{a}}\end{array}$ \\
\hline \multirow[t]{2}{*}{$\begin{array}{l}\text { Educate on healthy vs } \\
\text { unhealthy eating }\end{array}$} & $\begin{array}{l}\text { "Healthy eating guide to buy healthy foods or training for } \\
\text { parents to educate children on how and why certain foods are } \\
\text { healthy and not healthy for them." }\end{array}$ & 19 & 31 \\
\hline & $\begin{array}{l}\text { "Demonstrate healthy ways to eat by having program person } \\
\text { prepare and demonstrate that healthy food is good; example } \\
\text { of portion size to objects." }\end{array}$ & 6 & 18 \\
\hline \multirow[t]{3}{*}{ Parental involvement } & "Mentor-eat with child; set the example of how to eat healthy." & 9 & 27 \\
\hline & $\begin{array}{l}\text { "Access to available resources for amount of family activities; low } \\
\text { cost/inexpensive or free exercise." }\end{array}$ & 9 & 21 \\
\hline & "Program for kid/adults; support each other." & 4 & 12 \\
\hline \multirow[t]{3}{*}{ Effective program leaders } & "Coaching: reassurance no matter your size, no limits." & 9 & 24 \\
\hline & "Progress evaluation, positive weigh-in for kids." & 7 & 19 \\
\hline & $\begin{array}{l}\text { "Knowledgeable about disease/health consideration related to } \\
\text { culture." }\end{array}$ & 6 & 15 \\
\hline \multirow[t]{2}{*}{ Incentives } & "Fun, attractive to kids, and exciting to increase motivation." & 8 & 20 \\
\hline & "Gift cards to buy healthy foods." & 5 & 15 \\
\hline
\end{tabular}

${ }^{\mathrm{a}}$ Calculated by summing the ranks of responses $(3=$ most important, $2=$ second, and $1=$ least important). Higher score $=$ greater perceived importance.

\section{Themes from Probing Questions}

Parent Responses. Questions and major themes of parent responses are presented in Table 4. Across all 5 focus groups, parents identified 6 major types of resources that are currently available to them to help their children/adolescents have a healthy weight: the internet; electronic/digital tools and games (eg, "Fitbit" and "Wii Fit"); doctors and specialists, including nutritionists and trainers; school-related resources; private businesses; and community-level resources, including governmental programs (eg, "the library" and "YMCA").
Although all groups reported weight loss and weight maintenance as among the most important results they would expect from a WMP for children/adolescents, parents also stated they would expect cognitive, affective, and behavioral changes, such as increased self-esteem, increased knowledge about health behaviors, behavior change (eg, "healthy eating" and "increased activity"), and improved long-term health and lifestyle change.

Parents across groups reported that they would want to stick with a program if they were seeing progress or positive results (eg, "losing weight" and "feeling good").

Table 3. Children/Adolescents' Perceptions of How to Have a Healthy Weight $(n=30)$

\begin{tabular}{|c|c|c|c|}
\hline \multicolumn{4}{|c|}{ Specific question: What sorts of things could your doctor or a health coach teach you to help you have a healthy weight? } \\
\hline Key Themes & Representative Responses & $\begin{array}{l}\text { Total } \\
\text { Votes }\end{array}$ & $\begin{array}{l}\text { Sum of } \\
\text { Ranks }^{\mathrm{a}}\end{array}$ \\
\hline \multirow[t]{3}{*}{$\begin{array}{l}\text { Educate on healthy vs } \\
\text { unhealthy eating }\end{array}$} & $\begin{array}{l}\text { "Recommend a good meal plan for each day per week to have } \\
\text { the right nutrients and minerals to maintain a healthy body } \\
\text { weight." }\end{array}$ & 12 & 30 \\
\hline & $\begin{array}{l}\text { "Doctor can tell you what is healthy and not healthy and teach } \\
\text { the consequences of not eating healthy." }\end{array}$ & 6 & 18 \\
\hline & $\begin{array}{l}\text { "We could start training by doing a health plan or diet if our } \\
\text { parents are doing the same." }\end{array}$ & 2 & 4 \\
\hline \multirow[t]{2}{*}{ Exercise } & $\begin{array}{l}\text { "Fun activities; play games, basketball, dodgeball, jumping jacks, } \\
\text { dancing, and run with you to keep weight off." }\end{array}$ & 14 & 28 \\
\hline & $\begin{array}{l}\text { "Teach different exercise techniques and ways to work exercise } \\
\text { into your schedule." }\end{array}$ & 6 & 18 \\
\hline
\end{tabular}

\footnotetext{
${ }^{a}$ Calculated by summing the ranks of responses $(3=$ most important, $2=$ second, and $1=$ least important). Higher score $=$ greater perceived importance.
} 
Table 4. Themes From Probing Questions

\begin{tabular}{|c|c|c|c|}
\hline \multicolumn{2}{|c|}{ Parents' Focus Groups } & \multicolumn{2}{|c|}{ Children's Focus Groups } \\
\hline Questions & Themes & Questions & Themes \\
\hline $\begin{array}{l}\text { 1. What resources are } \\
\text { available to you } \\
\text { now to help your } \\
\text { child have a healthy } \\
\text { weight? }\end{array}$ & $\begin{array}{l}\text { Internet } \\
\text { Electronic/digital tools and games } \\
\text { Doctors/specialists } \\
\text { School } \\
\text { Businesses } \\
\text { Community (family)/government }\end{array}$ & $\begin{array}{l}\text { 1. What are ways that your } \\
\text { doctors, teachers, or } \\
\text { parents help you have a } \\
\text { healthy weight? }\end{array}$ & $\begin{array}{l}\text { Education/feedback } \\
\text { Encouragement/advice } \\
\text { Engage in activity } \\
\text { Monitor weight } \\
\text { Influence food intake }\end{array}$ \\
\hline $\begin{array}{l}\text { 2. What are the most } \\
\text { important results } \\
\text { you'd expect from a } \\
\text { weight } \\
\text { management } \\
\text { program for } \\
\text { children? }\end{array}$ & $\begin{array}{l}\text { Increased self-esteem (psychological } \\
\text { changes) } \\
\text { Weight loss (weight maintenance) } \\
\text { Improved health (long-term/lifestyle } \\
\text { change) } \\
\text { Increased knowledge about health } \\
\text { behaviors } \\
\text { Behavior change }\end{array}$ & $\begin{array}{l}\text { 2. What are the biggest } \\
\text { challenges that kids who } \\
\text { struggle with having a } \\
\text { healthy weight face? }\end{array}$ & $\begin{array}{l}\text { Bullying } \\
\text { Physical limitations } \\
\text { Behavioral and psychological } \\
\quad \text { struggles } \\
\text { Lack of knowledge } \\
\text { Lack of motivation } \\
\text { Lack of self-confidence } \\
\text { Tempting food } \\
\text { Lack of control over environment }\end{array}$ \\
\hline $\begin{array}{l}\text { 3. What would make } \\
\text { you want to stick } \\
\text { with a program, } \\
\text { even if you and } \\
\text { your child needed } \\
\text { to attend the } \\
\text { program every } \\
\text { week for several } \\
\text { months? }\end{array}$ & $\begin{array}{l}\text { Results } \\
\text { Convenient/flexible } \\
\text { Fun } \\
\text { Tangible incentives } \\
\text { Social support } \\
\text { Motivating - Good teacher/coach } \\
\text { Child interest }\end{array}$ & $\begin{array}{l}\text { 3. We're working with } \\
\text { doctors to create a } \\
\text { program to help kids and } \\
\text { parents become healthier. } \\
\text { If you were in this } \\
\text { program, what are the } \\
\text { most important results } \\
\text { you'd like to see? }\end{array}$ & $\begin{array}{l}\text { Visible results (weight loss) } \\
\text { Improved health-mental, physical, } \\
\quad \text { fitness, feeling better } \\
\text { Reduced bullying } \\
\text { Adopt healthy behaviors } \\
\text { Increased knowledge }\end{array}$ \\
\hline $\begin{array}{l}\text { 4. We are working } \\
\text { with primary care } \\
\text { providers to create } \\
\text { a program to help } \\
\text { treat obesity in } \\
\text { children; what } \\
\text { important factors } \\
\text { should a program } \\
\text { include to treat } \\
\text { childhood obesity? }\end{array}$ & $\begin{array}{l}\text { Education } \\
\text { Skills/behavior change } \\
\text { Incentives } \\
\text { Fun } \\
\text { Culturally appropriate } \\
\text { Social support/coaching } \\
\quad \text { (family-oriented) } \\
\text { Accessible, feasible, sustainable, } \\
\quad \text { affordable } \\
\text { Use of technology/apps websites }\end{array}$ & $\begin{array}{l}\text { 4. What would make you } \\
\text { want to stick with a } \\
\text { program, even if you } \\
\text { needed to go to the } \\
\text { program every week after } \\
\text { school for several months? }\end{array}$ & $\begin{array}{l}\text { Physical or visible results } \\
\text { Better health } \\
\text { Learning new skills } \\
\text { Better knowledge } \\
\text { Intrinsically } \\
\quad \text { rewarding-encouragement, } \\
\text { games, motivation } \\
\text { Tangible/material support } \\
\text { Emotional support } \\
\text { Strong relationship to program } \\
\text { staff } \\
\text { Social component }\end{array}$ \\
\hline $\begin{array}{l}\text { 5. What factors might } \\
\text { prevent your child } \\
\text { and you from } \\
\text { participation in a } \\
\text { weight } \\
\text { management } \\
\text { program? }\end{array}$ & $\begin{array}{l}\text { Time-related } \\
\text { Convenience-related } \\
\quad \text { (scheduling/conflicts) } \\
\text { Transportation } \\
\text { Lack of progress } \\
\text { Lack of support } \\
\text { Cost-related } \\
\text { Motivation-related } \\
\text { Negative emotions }\end{array}$ & $\begin{array}{l}\text { 5hat sorts of things could } \\
\text { your doctor or a health } \\
\text { coach teach you to help } \\
\text { you have a healthy } \\
\text { weight? }\end{array}$ & $\begin{array}{l}\text { General knowledge about } \\
\text { health/diet/exercise } \\
\text { Skills/tools } \\
\text { Education around habit/behavior } \\
\text { change and strategies } \\
\text { Combining education with actual } \\
\text { strategies for change } \\
\text { Scheduling conflicts/busy - } \\
\text { getting sick/emergencies } \\
\text { Lack of confidence/support } \\
\text { Not feeling prepared/supported } \\
\text { (external) } \\
\text { Low motivation (internal) } \\
\text { Stigma, getting bullied } \\
\text { Program is boring } \\
\text { Cost }\end{array}$ \\
\hline
\end{tabular}


Table 4. Continued

\begin{tabular}{|c|c|c|c|}
\hline \multicolumn{2}{|c|}{ Parents' Focus Groups } & \multicolumn{2}{|c|}{ Children's Focus Groups } \\
\hline Questions & Themes & Questions & Themes \\
\hline $\begin{array}{l}\text { 6. If we are successful } \\
\text { in developing } \\
\text { curriculum and } \\
\text { materials for a } \\
\text { family-based } \\
\text { weight } \\
\text { management } \\
\text { program, what } \\
\text { would that look } \\
\text { like? }\end{array}$ & $\begin{array}{l}\text { Digital/application-based } \\
\text { Individualized } \\
\text { Support } \\
\text { Incentives/motivation } \\
\text { Tips/resources, education } \\
\text { Behavioral prescriptions } \\
\text { Culturally appropriate }\end{array}$ & $\begin{array}{l}\text { 7. What sorts of fun activities } \\
\text { would you want to do } \\
\text { with your doctor or health } \\
\text { coach? } \\
\text { 8. What would help make } \\
\text { sure you and your parents } \\
\text { came to see your doctor } \\
\text { or health coach every } \\
\text { couple of weeks? }\end{array}$ & $\begin{array}{l}\text { Competitive games } \\
\text { Team games } \\
\text { Novelty/general fun } \\
\text { Fun (novel) } \\
\text { Results (progress visible) } \\
\text { Incentives (rewards) } \\
\text { Good relationship with coaches } \\
\quad \text { (welcoming/enjoyable) }\end{array}$ \\
\hline
\end{tabular}

Parents also reported that they would be more likely to stick to a program if it was accessible, fun, and interesting to their children/adolescents. Parents also reported that they would continue participating if the program provided tangible incentives, social support, and motivating coaches.

When asked to identify factors that might prevent them from participating in a program, parents reported factors related to time, scheduling conflicts, convenience, transportation, cost, motivation, and affect/emotion. Motivationrelated factors included fear, embarrassment, or judgment and low motivation stemming from prior failures when attempting to lose weight. Parents also mentioned that the presentation of the program "is key," including the name of the program and who the program is presented by, with some parents emphasizing that they would likely not participate if the program was not accommodating to health or disability issues and if it was not culturally sensitive. Parents across groups also reported that perceiving a lack of support and not seeing progress or results might also prevent them from participating.

Regarding important factors they would want included in a WMP for children/adolescents, parents thought a WMP should include educational components, involve skillbuilding and behavior change strategies, have incentives, be fun and positive, family-oriented, and culturally appropriate. The educational components suggested by the parents varied from general health education about the effects of diet, sleep, and excess weight on overall health to the nutritional components of foods and recommended portion sizes. Parents also noted that they would want a WMP to include social support (eg, "peer to peer support" and "community support") and coaching (eg, "life coaches" and "knowledgeable instructors"); that the program would need to be accessible, feasible, sustainable, and affordable; and that mobile or technological components could facilitate the program. These same themes were echoed in the responses to the question of what parents expected a successful WMP to look like.

Children/Adolescent Responses. Children/adolescents reported several ways that their parents, doctors, or teachers currently help them manage their weight, including providing education (eg, a teacher "talks to us about eating healthy and eating vegetables"); feedback (eg, "they can tell you what you're doing wrong"); encouragement and advice regarding healthy practices; monitoring their weight and helping them engage in activity and eat healthy foods; and limiting consumption of unhealthy foods.

Children/adolescents across the focus groups identified 3 major types of challenges that they face with maintaining a healthy weight: bullying, physical limitations, and psychological/behavioral struggles (eg, lack of knowledge, motivation, self-confidence, and self-control ["You think you can't change the way you are"] and lack of environmental control, such as family get-togethers, where unhealthy food is served).

Visible results were among the most-mentioned themes that children/adolescents said they would want to see in a program, but they also noted that they would want improved physical and psychological health, including improved fitness and increased self-esteem. Reduced bullying was another important result that children/adolescents across groups wanted. Children/adolescents also wanted to achieve successful adoption of healthy behaviors, including increasing their knowledge of healthy living, trying new healthy foods, and incorporating healthy habits into daily routines.

Children/adolescents reported that they would want to stick to the program if they saw physical results, learned new skills, gained knowledge about healthy living, and achieved better health overall. They also mentioned that a program that is fun and doesn't feel like school would make them more likely to stick with it. Children/adolescents stated that they would stick with a program if it had social components and if they perceived a strong relationship to program staff. These themes were echoed in the children/adolescent responses to the question of what factors would help them continue to attend the program sessions regularly. In particular, they said they would continue to be engaged if the program included incentives or rewards for healthy behaviors and fun and novel activities, including competitive or team games, if they had a good relationship with the health coach, and if they achieved visible progress.

Obstacles that would prevent children/adolescents from participating in the program were related to internal and external barriers. External barriers to participation were scheduling conflicts, cost of the program, lack of support or feeling unprepared (eg, "if you have to do it alone"), bullying, and a boring program that felt like a doctor's appointment. 
Internal obstacles that might prevent continued engagement in a WMP were lacking confidence or motivation and feeling embarrassed or stigmatized from bullying.

Both parents and their children/adolescents perceived that the program should be motivating, appealing, fun and educational, diverse, culturally appropriate, sustainable, and involve the entire family.

\section{DISCUSSION}

In this study, we examined the perceptions of parents, the majority of whom were African American, and their children/adolescents concerning the components that should be included in a family-based WMP adapted for a PCP setting and the perceived preferences, benefits, and barriers to participation. Although parents and their children/adolescents participated in separate focus groups, similar responses were expressed, apart from a few expected age-related differences. For example, during the preliminary questioning, all participants perceived that an expected result in a WMP is visible or tangible weight loss, which aligns with other research suggesting that participants may be inclined to expect that a WMP has a focus on physical results. ${ }^{37}$ However, parents and children/adolescents also both identified improved psychological well-being as a desired program outcome, including increased self-esteem, reduced bullying experiences, and improved self-confidence. These responses suggest that psychological well-being and physical health should be important targets of a family-based WMP.

Additionally, activities with family and friends that are fun and a team that encourages and provides support were viewed as necessities for participation in a family-based WMP. Research has shown that when an activity is fun and performed in a supportive atmosphere, participants are likely to remain in the study. ${ }^{37}$ Fun has also been identified in qualitative research as an enabler of program participation, particularly by adolescents. ${ }^{25}$ All groups overwhelmingly conveyed a desire for healthy vs unhealthy eating, a list of healthy foods including recipes, and cooking demonstrations to show that healthy eating is important and approachable. These similarities concur with research in which parents and children/adolescents with overweight and obesity expected that they would lose weight, especially if they were physically active and eating in a more healthy way ${ }^{38}$ and with research demonstrating that participants are most successful when they are shown how to implement healthy behaviors in addition to being told which behaviors to change. ${ }^{39,40}$

A major obstacle perceived by participants that would prevent participation in a WMP was time (parents' work schedules and kids' extracurricular activities), a finding that echoes previous research. ${ }^{26}$ In contrast, parents expressed concern about access to available resources and cost of the program, while children/adolescents expressed concerns about bullying preventing participation in a WMP. Multiple studies suggest that bullying is significantly associated with low selfesteem in overweight children/adolescents. ${ }^{41,42}$ Additionally, research has shown that differential participation might not result from a person's lack of willingness to participate but may be attributable to other causes such as time, access, or financial resources; these barriers may influence how researchers approach recruitment of populations that have been traditionally underrepresented in medical research. ${ }^{43-47}$
Parents commonly reported that if researchers were successful in developing curriculum and materials for a familybased WMP, these resources should be available online and/or accessible on a smartphone, suggesting that program delivery should be flexible. Thus, parents and their children/adolescents would have access to the program and the ability to participate when, where, and how at their convenience. Emerging evidence suggests that the best outcomes derive from multidisciplinary delivery approaches that use a broad range of expertise and varied interventions with proven collaboration. ${ }^{48}$

Parents across all groups perceived that the 3 most important strategies having the greatest impact in a family-based WMP would be education on healthy vs unhealthy eating, parental involvement, and effective program leaders, with parental involvement identified as the easiest to implement. Parental and/or familial involvement was critical for both parents and children/adolescents, as they expressed the need for support from each other for success and sustainability, as well as support from effective program leaders. To maintain long-term behavior change, children/adolescents with overweight and obesity and their parents need support from their extended family, school, friends, peers, and their PCP. ${ }^{38}$

Likewise, children/adolescents perceived that education on healthy vs unhealthy eating and exercise would have the greatest impact in a WMP, with healthy eating and meal plans identified as easiest to implement. Research has shown that nutritional and dietary consultation is one of the most useful supplementary services available in clinical practice for weight management. ${ }^{49,50}$

This study has several strengths. An advantage to using the NGT is that the weight of each participant's opinion is the same, and process loss seems less likely to occur. ${ }^{51}$ The highly structured format of the NGT provides an opportunity for group participants to achieve a substantial amount of work in a relatively short period of time. The NGT deliberately avoids interpretation from a facilitator who has the responsibility to explore but not interfere with or influence participants in the group. ${ }^{27}$

The NGT also has limitations: the composition and representativeness of participants may limit the generalizability of the results, training and preparation are required, the discussion is restricted to a single question, and further elaboration of other ideas is not allowed. ${ }^{52}$ However, coding and identification of common themes across the focus groups allowed for interpretation of other responses to complement the NGT findings. This study is further limited by its convenience sampling of available parents and their children/adolescents.

Overall, the results of this study suggest that parents and children/adolescents have similar perceptions and expectations of family-based WMPs in the primary care setting as they do of WMPs in other settings and face similar barriers. This study's findings also highlight the importance of psychosocial factors in family-based WMPs. Both parents and children/adolescents identified physical health and psychological well-being as desirable program results, suggesting that increasing self-esteem, helping adolescents cope with bullying, and helping improve overall mental well-being could be important targets in a WMP.

Future research exploring the design and implementation of FBTs for pediatric obesity in primary care settings could benefit from this study's findings. However, the present study 
also identifies several challenges. Delivering a high-quality WMP that is also fun, accessible, and supportive may be difficult for PCPs who are overburdened and in short supply. ${ }^{53}$ Similarly, future research will need to demonstrate the feasibility and cost-effectiveness of such programs.

\section{CONCLUSION}

Knowledge (education on healthy vs unhealthy eating), parental involvement that engages family and friends in activities such as dancing and games that are fun, and a knowledgeable team (effective program leaders) that provides incentives and support are the ingredients that parents and children/adolescents reported as necessary for success in family-based WMPs implemented in primary care. These findings may assist researchers in designing and planning sustainable interventions in future studies.

\section{ACKNOWLEDGMENTS}

Research reported in this article was funded through a Patient-Centered Outcomes Research Institute (PCORI) Award (PCS-2017C2-7542). The statements in this work are solely the responsibility of the authors and do not necessarily represent the views of the PCORI, the PCORI board of governors, or the PCORI methodology committee.

Additional support was provided by U54 GM104940 from the National Institute of General Medical Sciences of the National Institutes of Health (NIH), which funds the Louisiana Clinical and Translational Science Center and grant number T32 HL130357 from the National Heart, Lung, and Blood Institute (NHLBI), NIH. The content is solely the responsibility of the authors and does not necessarily represent the official views of the NIH.

Ava J Zebrick reports involvement with Novo Nordisk as an obesity ambassador outside the submitted work and is also employed by Ochsner Health outside the submitted work. Otherwise, the authors have no financial or proprietary interest in the subject matter of this article. The authors would like to thank the Pediatric Obesity and Health Behavior Laboratory staff and other staff members for providing assistance with logistics and for participating in a mock focus group for training purposes. A special thanks to all focus group participants from surrounding communities in Baton Rouge and Opelousas, Louisiana, for completing this study.

\section{REFERENCES}

1. Srivastava G, Fox CK, Kelly AS, et al. Clinical considerations regarding the use of obesity pharmacotherapy in adolescents with obesity. Obesity (Silver Spring). 2019;27(2):190-204. doi: 10.1002/oby.22385

2. Hales CM, Carroll MD, Fryar CD, et al. Prevalence of obesity among adults and youth: United States, 2015-2016. NCHS data brief, no. 288. Centers for Disease Control and Prevention. October 2017. Accessed December 30, 2020. www.cdc.gov/nchs/data/databriefs/db288.pdf

3. Skinner AC, Ravanbakht SN, Skeleton JA, Perrin E, Armstrong SC. Prevalence of obesity and severe obesity in US children, 1999-2016. Pediatrics. 2018;141(3):e20173459. doi: $10.1542 /$ peds.2017-3459

4. Finegood DT, Merth TD, Rutter H. Implications of the foresight obesity system map for solutions to childhood obesity. Obesity (Silver Spring). 2010;18 Suppl 1:S13-S16.

doi: $10.1038 /$ oby.2009.426
5. van Geel M, Vedder P, Tanilon J. Are overweight and obese youth more often bullied by their peers? A meta-analysis on the correlation between weight status and bullying. Int J Obes (Lond). 2014;38(10):1263-1267. doi: 10.1038/ijo.2014.117

6. Fox CL, Farrow CV. Global and physical self-esteem and body dissatisfaction as mediators of the relationship between weight status and being a victim of bullying. J Adolesc. 2009;32(5):1287-1301. doi: 10.1016/j.adolescence.2008.12.006

7. Griffiths LJ, Parsons TJ, Hill AJ. Self-esteem and quality of life in obese children and adolescents: a systematic review. Int J Pediatr Obes. 2010;5(4):282-304. doi: 10.3109/17477160903473697

8. Salahuddin M, Barlow SE, Pont SJ, Butte NF, Hoelscher DM. Development and use of an index for measuring implementation of a weight management program in children in primary care clinics in Texas. BMC Family Pract. 2018;19(1):191. doi: 10.1186/s12875-018-0882-7

9. Bass R, Eneli I. Severe childhood obesity: an under-recognized and growing health problem. Postgrad Med J. 2015;91(1081):639-645. doi: 10.1136/postgradmedj-2014-133033

10. Finkelstein EA, Khavjou OA, Thompson $\mathrm{H}$, et al. Obesity and severe obesity forecasts through 2030. Am J Prev Med. 2012;42(6):563-570. doi: 10.1016/j.amepre.2011.10.026

11. Huang TTK, Borowski LA, Liu B, et al. Pediatricians' and family physicians' weight-related care of children in the U.S. Am J Prev Med. 2011;41(1):24-32. doi: 10.1016/j.amepre.2011.03.016

12. Barlow SE, Bobra SR, Elliott MB, Brownson RC, Haire-Joshu D. Recognition of childhood overweight during health supervision visits: does BMI help pediatricians? Obesity (Silver Spring). 2007;15(1):225-232. doi: 10.1038/oby.2007.535

13. Turer CB, Mehta M, Durante R, Wazni F, Flores G. Parental perspectives regarding primary-care weight management strategies for school-age children. Matern Child Nutr. 2016;12(2):326-338. doi: 10.1111/mcn.12131

14. Turer CB, Upperman C, Merchant Z, Montano S, Flores G. Primary-care weight management strategies: parental priorities and preferences. Acad Pediatr. 2016;16(3):260-266. doi: 10.1016/j.acap.2015.09.001

15. Sallinen BJ, Schaffer S, Woolford SJ. In their own words: learning from families attending a multidisciplinary pediatric weight management program at the YMCA. Child Obes. 2013;9(3):200-207. doi: 10.1089/chi.2012.0106

16. Staiano AE, Marker AM, Comeaux J, Frelier JM, Hsia DS, Broyles ST. Family-based behavioral treatment for childhood obesity: caretaker-reported barriers and facilitators. Ochsner J. 2017;17(1):83-92.

17. Whitlock EP, O'Connor EA, Williams SB, Beil TL, Lutz KW. Effectiveness of weight management interventions in children: a targeted systematic review for the USPSTF. Pediatrics. 2010;125(2):e396-e418. doi: 10.1542/peds.2009-1955

18. Epstein LH, Paluch RA, Roemmich JN, Beecher MD. Family-based obesity treatment, then and now: twenty-five years of pediatric obesity treatment. Health Psychol. 2007;26(4):381-391. doi: 10.1037/0278-6133.26.4.381

19. Wilfley DE, Staiano AE, Altman M, et al.; Improving Access and Systems of Care for Evidence-Based Childhood Obesity Treatment Conference Workgroup. Improving access and systems of care for evidence-based childhood obesity treatment: conference key findings and next steps. Obesity (Silver Springs). 2017;25(1):16-29. doi: 10.1002/oby.21712

20. Robinson TN. Treating pediatric obesity: generating the evidence. Arch Pediatr Adolesc Med. 2008;162(12):1191-1192. doi: 10.1001/archpedi.162.12.1191 
21. Quattrin T, Roemmich JN, Paluch R, Yu J, Epstein LH, Ecker MA. Efficacy of family-based weight control program for preschool children in primary care. Pediatrics. 2012;130(4):660-666. doi: 10.1542/peds.2012-0701

22. Riggs KR, Lozano P, Mohelnitzky A, Rudnick S, Richards J. An adaptation of family-based behavioral pediatric obesity treatment for a primary care setting: group health family wellness program pilot. Perm J. 2014;18(3):4-10. doi: 10.7812/TPP/13-144

23. Taveras EM, Gortmaker SL, Mitchell KF, Gillman MW. Parental perceptions of overweight counseling in primary care: the roles of race/ethnicity and parent overweight. Obesity (Silver Spring). 2008;16(8):1794-801. doi: 10.1038/oby.2008.264

24. Davidson K, Vidgen $H$. Why do parents enrol in a childhood obestiy management program?: a qualitative study with parents of overweight and obese children. BMC Public Health. 2017;17(1):159. doi: 10.1186/s12889-017-4085-2

25. Smith KL, Straker LM, McManus A, Fenner AA. Barriers and enablers for participation in healthy lifestyle programs by adolescents who are overweight: a qualitative study of the opinions of adolescents, their parents and community stakeholders. BMC Pediatr. 2014;14:53. doi: 10.1186/1471-2431-14-53

26. Brennan L, Walkley J, Wilks R. Parent-and adolescent-reported barriers to participation in an adolescent overweight and obesity intervention. Obesity (Silver Spring). 2012;20(6):1319-1324. doi: 10.1038/oby.2011.358

27. Pena A, Estrada CA, Soniat D, Taylor B, Burton M. Nominal group technique: a brainstorming tool for identifying areas to improve pain management in hospitalized patients. $J$ Hosp Med. 2012;7(5):416-420. doi: 10.1002/jhm.1900

28. Castiglioni A, Shewchuk RM, Willett LL, Heudebert GR, Centor RM. A pilot study using nominal group technique to assess residents' perceptions of successful attending rounds. J Gen Intern Med. 2008;23(7):1060-1065. doi: 10.1007/s11606-008-0668-z

29. Crenshaw K, Shewchuk RM, Qu H, et al. What should we include in a cultural competence curriculum? An emerging formative evaluation process to foster curriculum development. Acad Med. 2011;86(3):333-341. doi: 10.1097/ACM.0b013e3182087314

30. Van de Ven AH, Delbecq AL. The nominal group as a research instrument for exploratory health studies. Am J Public Health. 1972;62(3):337-342. doi: 10.2105/ajph.62.3.337

31. Safford MM, Shewchuk R, Qu H, et al. Reason for not intensifying medications: differentiating "clinical inertia" from appropriate care. J Gen Intern Med. 2007;22(12):1648-1655. doi: 10.1007/s11606-007-0433-8

32. Corbie-Smith G, Thomas SB, Williams MV, Moody-Ayers S. Attitudes and beliefs of African Americans toward participation in medical research. $J$ Gen Intern Med. 1999;14(9):537-546. doi: 10.1046/j.1525-1497.1999.07048.x

33. Jefferson WK, Zunker C, Feucht JC, et al. Use of nominal group technique (NGT) to understand the perceptions of the healthiness of foods associated with African Americans. Eval Program Plann. 2010;33(4):343-348. doi: 10.1016/j.evalprogplan.2009.11.002

34. Elliott TR, Shewchuk RM. Problem solving therapy for family caregivers of persons with severe physical disabilities. In: Radnitz C, ed. Cognitive-Behavioral Interventions for Persons with Disabilities. Jason Aaronson; 2000:309-327.

35. Miller D, Shewchuk R, Elliot TR, Richards S. Nominal group technique: a process for identifying diabetes self-care issues among patients and caregivers. Diabetes Educ.
2000;26(2):305-310, 312, 314. doi: $10.1177 / 014572170002600211$

36. Shewchuk RM, O'Connor SJ, Fottler MD, Trinh H. Understanding the meaning of health care management research through the use of a cognitive mapping approach. Adv Health Care Manag. 2001;2:63-90. doi: 10.1016/S1474-8231(01)02023-7

37. Woolford SJ, Sallinen BJ, Schaffer S, Clark SJ. Eat, play, love adolescent and parent perceptions of the components of a multidisciplinary weight management program. Clin Pediatr(Phila). 2012;51(7):678-684. doi: $10.1177 / 0009922812440839$

38. Schalkwijk AAH, Bot SDM, de Vries L, Westerman MJ, Nijpels G, Elders PJM. Perspectives of obese children and their parents on lifestyle behavior change: a qualitative study. Int J Behav Nutr Phys Act. 2015;12:102. doi: 10.1186/s12966-015-0263-8

39. Burchett HED, Sutcliffe K, Melendez-Torres GJ, Rees R, Thomas J. Lifestyle weight management programmes for children: a systematic review using qualitative comparative analysis to identify critical pathways to effectiveness. Prev Med. 2018;106:1-12. doi: 10.1016/j.ypmed.2017.08.025

40. Kennedy BM, Champagne CM, Ryan DH, et al. The "Rolling Store:" an economical and environmental approach to the prevention of weight gain in African American women. Ethn Dis. 2009;19(1):7-12.

41. Danielsen YS, Stormark KM, Nordhus IH, et al. Factors associated with low self-esteem in children with overweight. Obes Facts. 2012;5(5):722-733. doi: 10.1159/000338333

42. White A, O'Brien B, Houlihan T, Darker C, O'Shea B. Childhood obesity: parents fail to recognise, general practitioners fail to act. Ir Med J. 2012;105(1):10-13.

43. Heerman WJ, Bennett WL, Kraschnewski JL, et al. Willingness to participate in weight-related research as reported by patients in PCORnet clinical data research networks. BMC Obes. 2018;5:10. doi: 10.1186/s40608-018-0187-3

44. Goff SL, Youssef Y, Pekow PS, et al. Successful strategies for recruitment of racial and ethnic minority pregnant women in a randomized controlled trial: the IDEAS for a healthy baby study. J Racial Ethn Health Disparities. 2016;3(4):731-737. doi: 10.1007/s40615-015-0192-x

45. Haley SJ, Southwick LE, Parikh NS, et al. Barriers and strategies for recruitment of racial and ethnic minorities: perspectives from neurological clinical research coordinators. J Racial Ethn Health Disparities. 2017;4(6):1225-1236. doi: 10.1007/s40615-016-0332-y

46. Erves JC, Mayo-Gamble TL, Malin-Fair A, et al. Needs, priorities, and recommendations for engaging underrepresented populations in clinical research: a ommunity perspective. $J$ Community Health. 2017;42(3):472-480. doi: 10.1007/s10900-016-0279-2

47. Kaiser BL, Thomas GR, Bowers BJ. Case study of engaging hard-to-reach participants in the research process: Community Advisors on Research Design and Strategies (CARDS) ${ }^{\oplus}$. Res Nurs Health. 2017;40(1):70-79. doi: 10.1002/nur.21753

48. Yanovski SZ, Yanovski JA. Long-term drug treatment for obesity: a systematic and clinical review. JAMA. 2014;311(1):74-86. doi: 10.1001/jama.2013.281361

49. Huang J, Yu H, Marin E, Brock S, Carden D, Davis T. Physicians' weight loss counseling in two public hospital primary care clinics. Acad Med. 2004;79(2):156-161. doi: 10.1097/00001888-200402000-00012

50. Elson RB, Splett PL, Bostick RM, Aeppli D, Haberman M. Dietitian practices for adult outpatients with hypercholesterolemia referred by physicians. The Minnesota 
Dietitian Survey. Arch Fam Med. 1994;3(12):1073-1080. doi: 10.1001/archfami.3.12.1073

51. Gallagher M, Hares T, Spencer J, Bradshaw C, Webb I. The nominal group technique: a research tool for general practice? Fam Pract. 1993;10(1):76-81. doi: 10.1093/fampra/10.1.76

52. Gaining consensus among stakeholders through the nominal group technique. Centers for Disease Control and Prevention.
Updated August 2018. Accessed December 23, 2020. www.cdc.gov/HealthyYouth/evaluation/pdf/brief7.pdf

53. Bodenheimer T, Pham HH. Primary care: current problems and proposed solutions. Health Aff (Millwood). 2010;29(5):799-805. doi: 10.1377/hlthaff.2010.0026

This article meets the Accreditation Council for Graduate Medical Education and the American Board of Medical Specialties Maintenance of Certification competencies for Patient Care, Medical Knowledge, and Practice-Based Learning and Improvement.

(C2021 by the author(s); licensee Ochsner Journal, Ochsner Clinic Foundation, New Orleans, LA. This article is an open (c) (i) access article distributed under the terms and conditions of the Creative Commons Attribution (CC BY) license (creativecommons.org/licenses/by/4.0/legalcode) that permits unrestricted use, distribution, and reproduction in any medium, provided the original author(s) and source are credited. 